\title{
Rancang Bangun Alat Penghancur Sampah Botol Plastik Kapasitas \pm 33 Kg/Jam
}

\author{
Firmansyah Burlian, Irsyadi Yani, Ivfransyah \& Jhosua ArieS. \\ Jurusan Teknik Mesin, Fakultas Teknik, Universitas Sriwijaya \\ Jl. Palembang-Prabumulih KM.32 Ogan Ilir, Sumatera Selatan \\ E-mail: firmansyahburlian@unsri.ac.id
}

\begin{abstract}
Abstrak- Semakin bertambah jumlah sampah botol plastik setiap tahunnya meningkatkan kerusakan lingkungan, sehingga harus dilakukan pengolahan sampah botol plastik dengan cara didaur ulang. Salah satu proses pendaur ulangan adalah dengan cara dihancurkan sebelum dicairkan. Mesin penghancur sampah botol plastik yang dirancang berukuran (620 mm $x 420 \mathrm{~mm} \times 800 \mathrm{~mm}$ ). Daya utama penggerak mesin menggunakan motor listrik $1 \mathrm{hp}$ (746 watt) dengan putaran poros motor 1400 rpm. Kapasitas mesin yang dirancang sebesar $\pm 33 \mathrm{~kg} / \mathrm{jam}$ sehingga membutuhkan putaran poros sebesar $126 \mathrm{rpm}$. Tipe pisau yang digunakan berdiameter 120 mm dengan bentuk cakram yang memiliki 4 pisau potong setiap ujungnya. Mesin menggunakan dua poros yang berputar dengan 7 buah pisau penghancur yang diletakkan setiap porosnya. Penelitian bertujuan untuk mengetahui waktu dan ukuran hasil potongan sampah botol plastik dengan tiga bentuk susunan yang akan dicoba menggunakan botol plastik seberat $1 \mathrm{~kg}$. Bentuk pertama menghasilkan potongan berukuran 4,5-10 cm dengan waktu 108,22 detik. Bentuk kedua menghasilkan potongan berukuran 4-8,5 cm dengan waktu 112,19 detik. Bentuk ketiga memerlukan waktu 110,15 detik dengan ukuran 4,3-9 $\mathrm{cm}$.
\end{abstract}

Kata kunci: botol plastik, daur ulang botol plastik, mesin penghancur, pisau penghancur

\section{PENDAHULUAN}

Indonesia merupakan negara dengan populasi yang besar didunia dan dikenal dengan negara kepulauan yang terletak didaerah tropis dan memiliki potensi ekonomi yang besar untuk masa yang akan datang. Jumlah penduduk semakin meningkat dari tahun ke tahun begitu juga dengan penggunaan botol plastik semakin meningkat sehingga Sampah plastik jumlahnya semakin lama semakin bertambah, walaupun plastik memiliki dampak negatif pada lingkungan sebagai limbah, namun plastik dapat didaur ulang sehingga dimungkinkan penggunaannya menjadi produk lain (Yamin, M, Satyadarma, D. \& Naipospos, P., 2008). Dalam pengolahan sampah hendaknya menerapkan proses-proses, seperti Reduce (mengurangi), Reuse (menggunakan kembali), Recycle (mendaur ulang), Replace (mengganti barang berpotensi sampah botol plastik ke arah bahan recycle). Untuk menunjang langkah tersebut maka dibuat suatu perancangan mesin untuk mengolah sampah. Permasalahan mengenai pengolahan sampah telah menunjang timbulnya banyak inovasi-inovasi teknologi yang bertujuan untuk mengurangi pencemaran lingkungan. Pengolahan sampah botol plastik ini dimaksudkan untuk memproses limbah botol plastik menjadi sesuatu yang dapat bermanfaat dan mengurangi dampak buruk terhadap lingkungan. Melihat data dan kenyataan sampah botol plastik yang ada dilapangan penulis mencoba untuk merancang dan membuat mesin pencacah sampah botol plastik Bentuk mesin penghancur ini memiliki konstruksi yang kuat dan kokoh serta ringkas dan sederhana. Pada pengoperasian mesin ini tidak perlu membutuhkan operator atau teknisi dengan kualifikasi tertentu karena mesin ini sangat mudah digunakan, serta dari pemotongannya didapatkan hasil cacahan yang berbentuk serpihan kecil-kecil (Junaidi, Nur, I., Nofriadi \& Rusmardi, 2015). Alat penghancur botol plastik yang dirancang ini memiliki susunan mata pisau yang mampu menghasilkan kapasitas $\pm 33 \mathrm{~kg} / \mathrm{jam}$.

\section{LANDASAN TEORI}

Plastik yang akan dihancurkan adalah plastik yang sudah dikumpulkan dari jenis-jenis plastik yang tidak terpakai yang berasal dari minuman. Pihak-pihak industri kecil terpikir mengolah botol plastik bekas untuk di daur ulang, sehingga muncul ide untuk merancang mesin penghancur plastik yang memiliki harga terjangkau dan efisien. Mesin plastik itu sendiri adalah mesin yang digunakan untuk menghancurkan wadah plastik menjadi ukuran yang lebih kecil. Jenis plastik yang digunakan adalah botol plastik bekas minuman, wadah plastik yang dihancurkan oleh penghancur plastik menjadi serpihan yang lebih kecil (Rajagukguk, J., 2013). Prinsip - prinsip yang dapat diterapkan dalam penanganan sampah misalnya dengan penerapan prinsip 3-R, 4-R atau 5-R. Penanganan sampah 3-R adalah konsep penanganan sampah dengan cara reduce (mengurangi), reuse (menggunakan kembali), recycle (mendaur ulang sampah), sedangkan 4-R ditambah Replace (mengganti) mulai dari sumbernya. Prinsip 5-R selain 4 prinsip tersebut diatas ditambah lagi dengan Replant (menanam kembali). Penanganan sampah 4-R penting untuk dilaksanakan 
dalam rangka pengolahan sampah adat yang sangat efisien dan efektif (Fadillah, A., 2015). Pada mesin penghancur ini memiliki bagian utama guna mendukung fungsi mesin tersebut. Komponen utama pada mesin penghancur ini adalah :

1. Motor listrik

Alat yang memiliki komponen utamanya stator dan rotor adalah motor listrik (Sutowo, C., Diniardy, E. \& Maryanto, 2011). Motor listrik tersebut akan mengikutsertakan kedua kumpulan lilitan yang dililitkan pada atau yang ditanamkan dalam celah besi. Satu atau kedua lilitan dapat dialiri. Fungsi dari motor listrik disini untuk mengubah energy listrik menjadi energy mekanik (putaran). Motor listrik merupakan sebuah alat yang terdiri dari dua komponen utama yaitu stator oleh arus bolak balik atau arus searah, maka rotor dan stator harus dililitkan untuk kutub yang sama banyaknya supaya menghasilkan sebuah motor listrik.

\section{Transmisi}

Transmisi adalah suatu alat untuk meneruskan tenaga dari poros satu ke poros yang lain dibantu dengan alat yang sesuai dengan kebutuhan, misalnya alat itu sabuk, rantai, gear dll (Triantoko,dkk, 2015).

\section{Bantalan}

Bantalan merupakan salah satu elemen mesin yang memiliki fungsi untuk menumpu poros berbeban agar dapat bekerja secara halus, aman dan panjang umurnya pada setiap putaran atau gerakan bolakbaliknya. Agar poros searea elemen mesin dapat bekerja dengan baik, maka bantalan harus kokoh. (Sularso dan Suga, K., 2013).

4. Poros

Poros dalam sebuah mesin berfungsi untuk meneruskan tenaga bersama-sama dengan putaran. Setiap elemen mesin yang berputar, seperti cakara tali, puli sabuk mesin, piringan kabel, tromol kabel, roda jalan dan roda gigi dipasang berputar terhadap poros dukung yang berputar. Contoh poros dukung yang berputar yaitu poros roda keran pemutar gerobak.

\section{Pasak}

Pasak adalah suatu elemen mesin yang digunakan untuk menetapkan bagian - bagian mesin seperti roda gigi, sproket, pulli, kopling, dll (Sularso dan Suga, K., 2013). Pada poros momen akan diteruskan dari poros ke naf atau dari naf ke poros. Pasak luncur memungkinkan pergeseran aksial roda gigi, dll. Pada porosnya, seperti pada seplain. Yang paling umum dipakai adalah pasak benam yang dapat meneruskan momen yang besar. Untuk momen Copyright ( 1019 FT-UHAMKA. - All rights reserved DOI: 10.22236/teknoka.v\%vi\%i.4286 dengan tumbukan, dapat dipasang pasak singgung.

6. Pisau potong

Pisau potoh dibutuhkan untuk menghancurkan sampah botol plastik, dimana untuk dapat menghancurkan botol plastik menjadi bagian potongan kecil pisau potong yang memiliki kekuatan dan ketajaman. (Sutowo, C., Diniardy, E. \& Maryanto, 2011). Pisau potong haruslah memiliki sudut ketajaman tertentu. Hal ini berpengaruh kepada konstruksi pisau potong itu sendiri. Apabila pisau potong memiliki sudut yang terlalu lancip maka pisau potong akan menjadi tipis yang dapat mengakibatkan pisau potong cepat rusak. Sebaliknya apabila pisau potong memiliki sudut ketajaman yang tumpul maka akan terjadi kesulitan pada saat penghancuran botol plastik. Mata daripada pisau potong di assembly pada dudukan pisau potong yang ada dengan cara dibaut. Mata pisau potong tersebut terbuat dari baja karbon, dan sifat kekerasannya harus lebih keras dari material yang akan dipotong.

\section{METODOLOGI PENELITIAN}

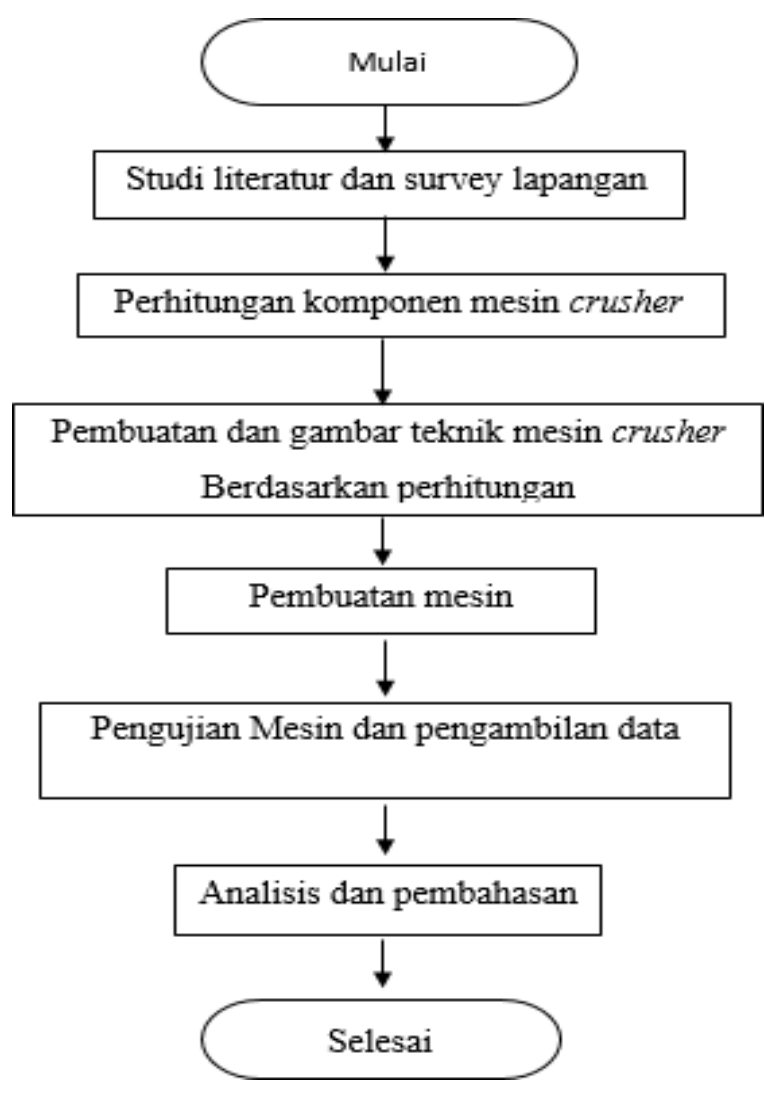

Gambar 1 Diagram Alir Penelitian

Pada perancangan mesin penghancur sampah botol plastik yang didukung oleh komponen-komponen yang baik dan terencana ini diharapkan dapat berjalan baik dan terhindar dari kegagalan pada saat operasi

Seminar Nasional TEKNOKA ke - 4, Vol. 4, 2019

ISSN No. 2502-8782 
berlangsung. Parameter yang akan dihitung pada perancangan ini berupa :

1. Perhitungan daya motor penggerak

2. Perancangan dan analisa kekuatan poros

3. Perhitungan dan perancangan pasak

4. Perancangan puli

5. Perencanaan sabuk

Alat yang sudah dirancang tersebut kemudian akan dilakukan uji coba dengan fokus pengujiannya pada variasi bentuk susunan mata pisau terhadap waktu yang diperlukan dan ukuran hasil cacahan. Variasi bentuk susunan mata pisau yang akan diuji terdapat tiga macam seperti yang terlihat pada gambar 3, gambar 4 dan gambar 5.

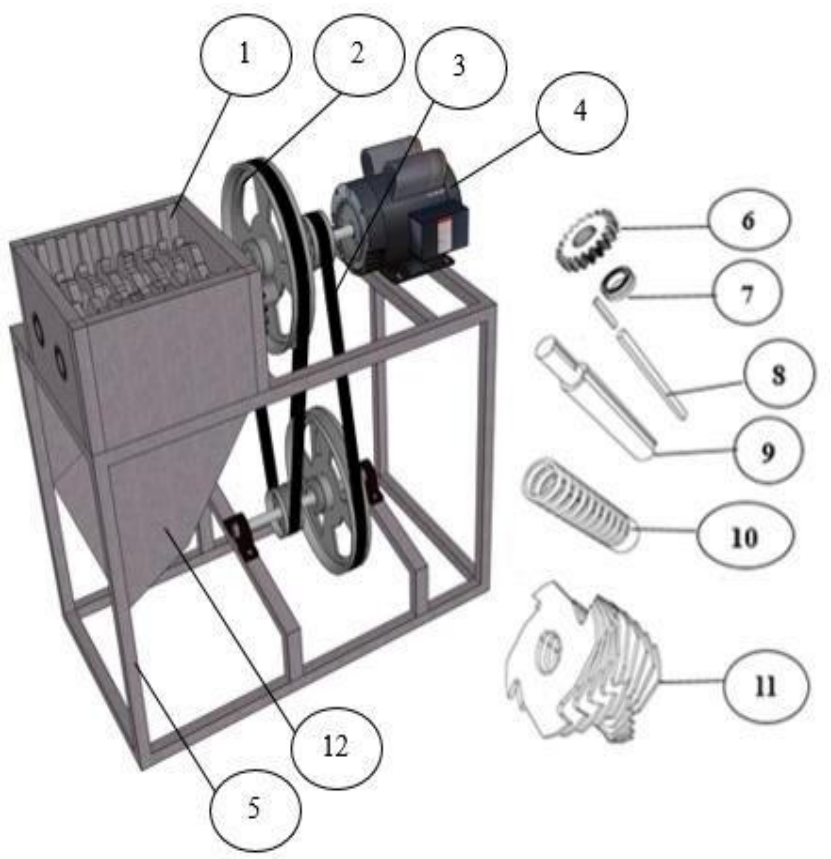

Gambar 2 Perancangan Alat Penghancur Sampah Botol Plastik

Dimana :

1. Ruang pencacah

2. Puli

3. Sabuk

4. Motor listrik

5. Rangka

6. Roda gigi

7. Bantalan (Bearing)

8. Pasak

9. Poros

10. Pemisah pisau pencacah

11. Pisau pencacah

12. Tempat keluar hasil cacahan

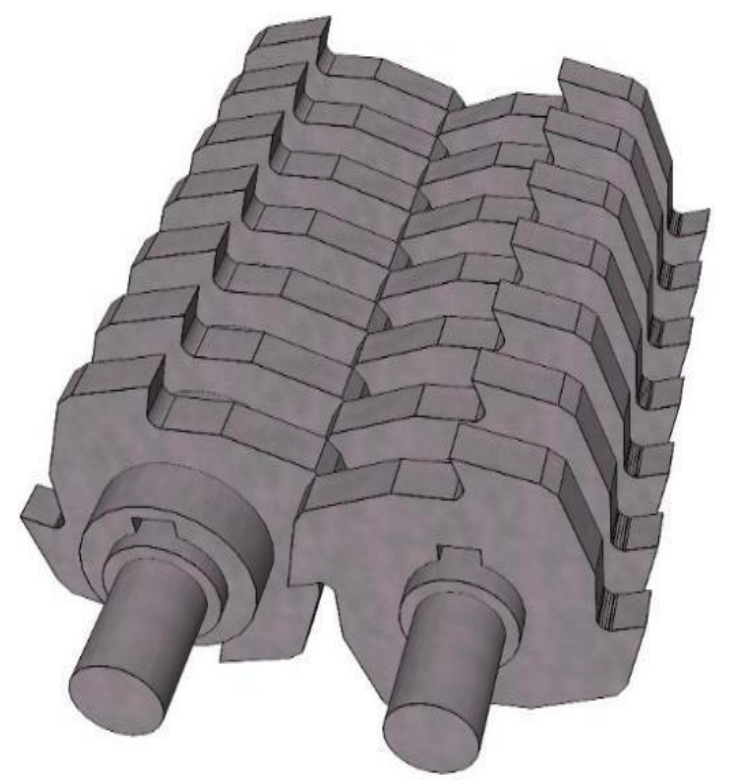

Gambar 3 Susunan bentuk lurus

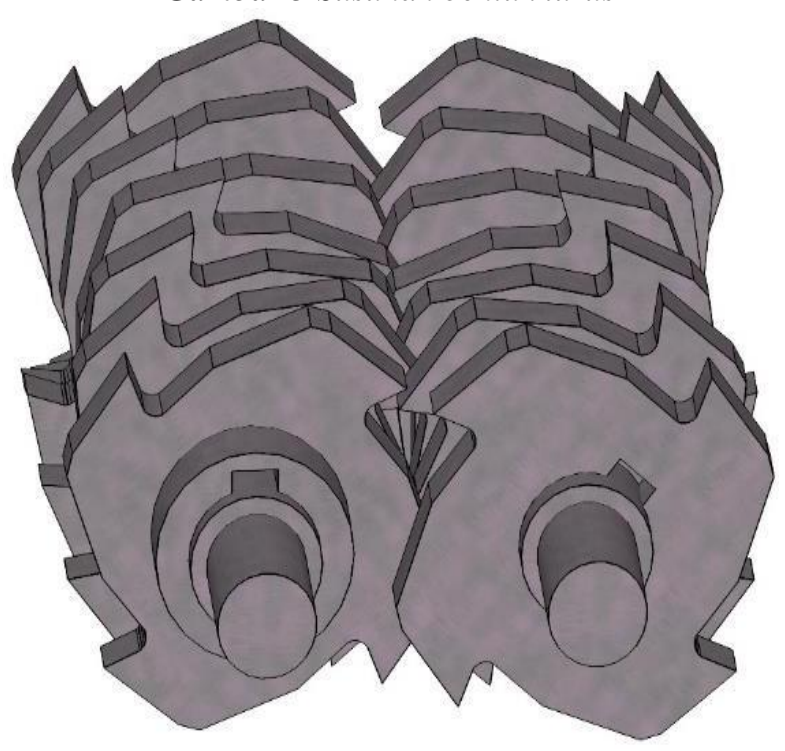

Gambar 4 Susunan bentuk X

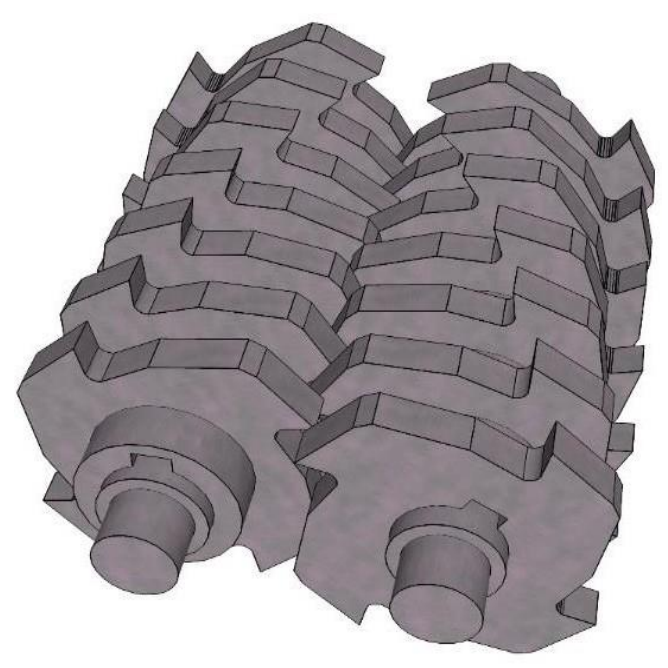

Gambar 5 Susunan bentuk V

Seminar Nasional TEKNOKA ke - 4, Vol. 4, 2019 ISSN No. 2502-8782 


\section{HASIL DAN PEMBAHASAN}

Perancangan alat penghancur sampah botol plasik bekas minuman akan dilakukan perhitungan berupa, putaran minimum mesin yang diperlukan, perhitungan dan analisa daya motor listrik, perencanaan dan perhitungan poros, perancangan pasak, dan yang terakhir perancangan mata pisau. Selanjutnya alat tersebut akan diuji berdasarkan variasi bentuk susunan mata pisaunya.

\subsection{Putaran Minimum Mesin}

Empat kali pemotongan diihasilkan dari satu buah cakram yang mempunyai empat buah mata pisau melakukan satu putaran poros. Tinggi satu mata pisau sebesar 1,6 cm, mengingat tinggi botol plastik sebesar $20 \mathrm{~cm}$, dan pemotongan botol plastik diasumsikan akan terjadi secara vertikal atau secara tegak lurus. Sehingga satu botol plastik akan membutuhkan 12,5 kali pemotongan, mengingat adanya keterbatasan pada sistem maka penghancuran plastik diasumsikan terjadi 13 kali pemoongan. Agar pemotongan terjadi sebanyak 13 kali maka poros harus berputar sebanyak 3,25 kali.

Setelah diketahui satu botol plastik beratnya 17 gram dan satu botol plastik membutuhkan 3,25 kali putaran agar dapat hancur, maka satu putaran poros akan menghasilkan 5,23 gram atau $0,0052 \mathrm{~kg}$. Agar perencanaan sebesar $33 \mathrm{~kg} / \mathrm{jam}$ atau $0,55 \mathrm{~kg} /$ menit dapat tercapai, maka putaran poros yang diperlukan dapat diperhitungkan dengan kapasitas rencana dibagi berat hasil dari pemotongan per satu putaran poros, seperti berikut ini

$$
\frac{0,55 \mathrm{~kg} / \mathrm{menit}}{0.0052 \mathrm{~kg}}=105 \mathrm{rpm}
$$

Untuk memenuhi kapasitas mesin yang akan direncanakan dan botol plastik tersebut dapat hancur disegala kondisi maka pada perancangan ini akan diberikan faktor keamanan $\mathrm{Sfp}=1,2$

$$
105 \times 1,2=126 \mathrm{rpm}
$$

\subsection{Analisa Perhitungan Daya Motor Penggerak}

$$
\mathrm{F}=\tau \times \mathrm{A}
$$

Dimana :

$\mathrm{F}=$ Gaya yang diperlukan $(\mathrm{N})$

$\tau=$ Tegangan geser yang diizinkan $\left(\mathrm{N} / \mathrm{mm}^{2}\right)$ $=21,725 \mathrm{~N} / \mathrm{mm}^{2}$

$\mathrm{A}=$ Luas Penampang $=60 \mathrm{~mm} \times 0,48 \mathrm{~mm}$ $=28,8 \mathrm{~mm}^{2}$

$\mathrm{F}=21,725 \mathrm{~N} / \mathrm{mm}^{2} \times 28,8 \mathrm{~mm}^{2}=625,68 \mathrm{~N}$

Selanjutnya akan dihitung total torsi (Nm) yang

Copyright (C) 2019 FT-UHAMKA. - All rights reserved DOI: $10.22236 /$ teknoka.v\%vi\%i.4286 gaya pemotong atau torsi yang dipengaruhi momen inersia.

$$
\mathrm{T}_{\mathrm{b}}=\mathrm{F} \times \mathrm{r}
$$

Dimana :

$\mathrm{T}_{\mathrm{b}}=$ Torsi Beban $(\mathrm{N} / \mathrm{m})$

$\mathrm{F}=$ Gaya yang diperlukan $=625,68 \mathrm{~N}$

$\mathrm{r} \quad=$ jari jari pisau pemotong $=0.06 \mathrm{~m}$

$\mathrm{T}=625,68 \mathrm{~N} \times 0.06 \mathrm{~m}=37,54 \mathrm{Nm}$

$$
\mathrm{T}_{\mathrm{tb}}=\mathrm{Ix} \alpha
$$

diperlukan yaitu torsi pada saat proses pemotongan dan torsi pada saat poros dan pisau tidak mendapat

Dimana :

$$
\begin{aligned}
& \mathrm{T}_{\mathrm{tb} .}=\text { Torsi Tanpa Beban }(\mathrm{N} / \mathrm{m}) \\
& \text { I }=\text { Momen Inersia }\left(\mathrm{kgm}^{2}\right)=1 / 2 \cdot \mathrm{m}, \mathrm{r}^{2} \\
& I=1 / 2[4 \mathrm{~kg}+2,45 \mathrm{~kg}+(0.92 \mathrm{~kg} \mathrm{x} 7)](0.06 \mathrm{~m})^{2} \mathrm{I} \\
& =0.0232 \mathrm{kgm}^{2} \\
& \alpha=\frac{\omega}{t}\left(\mathrm{rad} / \mathrm{s}^{2}\right) \\
& \omega=\text { Kecepatan sudut }(\mathrm{rad} / \mathrm{s})
\end{aligned}
$$

$\omega=\frac{2, \pi \cdot n}{60}=\frac{2,3,14,126}{60}=13,2 \mathrm{rad} / \mathrm{s}$
$\alpha=\frac{13,2 \mathrm{rad} / \mathrm{s}}{5 s}=2,64 \mathrm{rad} / \mathrm{s}^{2}$
$\mathrm{~T}_{\mathrm{tb} . .}=0,0232 \mathrm{kgm}^{2} .2,64 \mathrm{rad} / \mathrm{s}^{2}=0,061 \mathrm{Nm}$

Torsi Total $=\mathrm{T}_{\mathrm{b}}+\mathrm{T}_{\mathrm{tb}}$

$$
\begin{aligned}
& =37,54 \mathrm{Nm}+0.061 \mathrm{Nm} \\
& =37,6 \mathrm{Nm}
\end{aligned}
$$

$$
\mathrm{P}=\mathrm{T} \times \omega
$$

Dimana :

$\mathrm{P}=$ Daya yang diperlukan (watt) $\mathrm{T}$

$=$ Torsi $=37,6 \mathrm{Nm}$

$\omega=$ Kecepatan sudut $(\mathrm{rad} / \mathrm{s})$

$\omega=\frac{2 . \pi \cdot n}{60}=\frac{2.3,14: 126}{60}=13,2 \mathrm{rad} / \mathrm{s}$

$\mathrm{P}=37,6 \mathrm{Nm} \times 13,2 \mathrm{rad} / \mathrm{s}=496,32 \mathrm{watt}$

Daya yang diperlukan untuk menghancurkan botol plastik adalah 496,32 watt. Faktor keamanan Sfp $=1,5$ diberikan agar daya rencana dapat menghancurkan botol plastik di segala kondisi 496,32 watt $\mathrm{x} 1,5=744,48$ watt

\subsection{Analisa Perhitungan dan Perancangan Poros}

Perancangan poros mesin penghancur botol plastik yang akan diperhitungkan hanya torsi atau momen puntirnya saja dan tidak memperhitungkan momen lentur yang terjadi ini dikarenakan beban ditumpu poros yang tidak terlalu besar pada saat bekerja secara vertical.

\footnotetext{
Seminar Nasional TEKNOKA ke - 4, Vol. 4, 2019 ISSN No. 2502-8782
} 
Lendutan yang akan terjadi juga diabaikan dikarenakan panjang poros tidak terlalu panjang pada saat akan dirancang.

$$
\tau_{a a}=\frac{\sigma}{S_{f 1} \times S_{f 2}}
$$

Ket :

$\tau_{\bar{\alpha}} \quad=$ Tegangan geser yang diizinkan $\left(\mathrm{N} / \mathrm{mm}^{2}\right)$

$\sigma \quad=$ Kekuatan tarik $\left(\mathrm{N} / \mathrm{mm}^{2}\right)=360 \mathrm{~N} / \mathrm{mm}^{2}$

$S f_{1} \quad=$ Faktor Keamanan bahan

- $S f=5.6$

- $S$-c $=6.0$ (bila pengaruh massa dan baja paduan)

$S f_{2}=$ Faktor keamanan akibat alur pasak (1.3-3.0)

$$
\begin{gathered}
\tau_{a}=\frac{360 \mathrm{~N} / \mathrm{mm}^{2}}{6.0 \times 3.0}=20 \mathrm{~N} / \mathrm{mm}^{2} \\
T=\frac{\pi}{16} \tau_{a} d^{3}
\end{gathered}
$$

Ket :

$\mathrm{T}=$ Torsi pada poros $=37,6 \mathrm{Nm} \tau_{a}=$ Tegangan geser yang diizinkan

$$
\begin{aligned}
& =20 \mathrm{~N} / \mathrm{mm}^{2} \\
d & =\frac{16 \times 37,6 \times 10^{8} \mathrm{Nmm}}{3.14 \times 20 \mathrm{~N} / \mathrm{mm}^{2}}=\frac{601600 \mathrm{Nmm}}{62.8 \mathrm{~N} / \mathrm{mm}^{2}} \\
d^{3} & =9579,62 \mathrm{~mm}^{3} \\
d & =21,24 \mathrm{~mm}
\end{aligned}
$$

Diameter minimal yang dibutuhkan pada perancangan poros ini sebesar $21,24 \mathrm{~mm}$, maka pada perancangan ini dibuat poros bertingkat dimana pada sisi bantalan akan dirancang dengan diameter $30 \mathrm{~mm}$ dan pada sisi pisau pemotongnya dibuat dengan diameter $40 \mathrm{~mm}$.

$$
\tau=\frac{5,1 . T}{d^{3}}
$$

Ket :

$\mathrm{T}=$ Tegangan geser yang timbul $\left(\mathrm{N} / \mathrm{mm}^{2}\right)$

$T=$ Torsi pada poros $=37,6 \mathrm{Nm}$

$$
=37,6 \times 10^{3} \mathrm{Nmm}
$$

$\mathrm{d}=$ diameter $=\frac{30 \mathrm{~mm}+40 \mathrm{~mm}}{2}=35 \mathrm{~mm}$

T $\quad=\frac{5_{1} 1 \times 37,6 \times 10^{\mathrm{a}} \mathrm{Nmm}}{35 \mathrm{~mm}^{\mathrm{a}}}=\frac{191760 \mathrm{Nmm}}{42875 \mathrm{~mm}^{\mathrm{a}}}$

$\mathrm{T}=4,4725\left(\mathrm{~N} / \mathrm{mm}^{2}\right)$

Jadi pada perancangan poros di mesin penghancur botol plastik dapat dikatakan aman karena tegangan geser yang timbul lebih kecil dari tegangan geser yang diizinkan.

$$
\tau_{a(20 \mathrm{~N} / \mathrm{m} 2)}>\tau(4,4725 \mathrm{~N} / \mathrm{mm} 2)
$$

\subsection{Analisa Perhitungan dan Perancangan Pasak}

Analisa dan perhitungan perancangan pasak hanya akan dilakukan terhadap panjang minimum pasak yang diperlukan untuk menahan momen puntir atau torsi lebar pasak tidak diperhitungkan kembali karena standar tebal dan lebar pasak dapat dilihat pada tabel 1.

Tabel 1 Standar tebal dan lebar pasak (Khurmi, R. S. \& Gupta, J. K., 2005)

\begin{tabular}{|c|c|c|}
\hline \multirow{2}{*}{$\begin{array}{c}\text { Diameter Poros } \\
(\mathrm{mm})\end{array}$} & \multicolumn{2}{|c|}{ Ukuran Pasak } \\
\cline { 2 - 3 } & Lebar $(\mathrm{mm})$ & Tebal $(\mathrm{mm})$ \\
\hline 38 & 12 & 8 \\
\hline 44 & 14 & 9 \\
\hline
\end{tabular}

$$
T=\operatorname{lx} w x \tau_{\mathbb{L}} x \frac{d}{2}
$$

Ket :

$\mathrm{T}=$ Torsi yang ditransmisikan poros

$l \quad=$ Panjang minimum pasak

$\mathrm{w}=$ Lebar minimum pasak $=13 \mathrm{~mm}$

$\tau_{\alpha} \quad=$ Tegangan geser yang diizinkan

$=20 \mathrm{~N} / \mathrm{mm}^{2}$

$\mathrm{d}=$ Diameter poros $=40 \mathrm{~mm}$

$\mathrm{T} \quad=l x w x \tau_{\pi} x \frac{d}{2}$

$=l \times 13 \mathrm{~mm} \times 20 \mathrm{~N} / \mathrm{mm}^{2} \times 40 \mathrm{~mm} / 2$

$\mathrm{T} \quad=l \times 5200 \mathrm{Nmm}$

$$
T=\frac{\pi}{16} \tau_{\pi} d^{\pi}
$$

Ket :

$\mathrm{T}=$ Torsi yang ditransmisikan poros

$\tau_{\tilde{\omega}} \quad=$ Tegangan geser yang diizinkan

$=20 \mathrm{~N} / \mathrm{mm}^{2}$

$\mathrm{d}=$ Diameter poros $=40 \mathrm{~mm}$

$\mathrm{T}=\frac{\mathrm{a} 14}{16} 20 \mathrm{~N} / \mathrm{mm}^{2}(40 \mathrm{~mm})^{3}=251200 \mathrm{Nmm}$

Panjang minimum pasak ( $l$ ) didapat dari hasil subsitusi kedua persamaan diatas

$l=\frac{251200}{5200}=48.31 \mathrm{~mm}$

Jadi, perancangan yang akan dilakukan pada mesin penghancur botol plastik dibuat dengan lebar $14 \mathrm{~mm}$, tebal $10 \mathrm{~mm}$ dan panjang $224 \mathrm{~mm}$. Hal tersebut dilakukan agar dapat menghindari terjadinya kegagalan pada saat pengoperasian.

Seminar Nasional TEKNOKA ke - 4, Vol. 4, 2019 ISSN No. 2502-8782 


\subsection{Perhitungan Puli}

Pada perancangan mesin penghancur botol plastik ini menggunakan puli bertingkat. Pada saat perhitungan dimasukkan kondisi slip dengan asumsi $2 \%$, hal ini dilakukan agar ketelitian pada perancangan akan meningkat.

kemudian ditransmisikan oleh poros. Tebal dan

$$
\frac{N_{m}}{N_{p}}=\frac{d_{1} d_{3}}{d_{2} d_{4}}\left[1-\left(\frac{s_{1}+s_{2} s_{3}+s_{4}}{100}\right)\right.
$$

Ket :

$$
\begin{array}{ll}
n_{m} & =\text { Putaran motor }(\mathrm{rpm})=1400 \mathrm{rpm} \\
n_{p} & =\text { Putaran poros }(\mathrm{rpm})=126 \mathrm{rpm} \\
d_{2} d_{4} & =\text { diameter puli kecil }(\mathrm{in})=3 \mathrm{in} \\
& =76,2 \mathrm{~mm} \\
d_{1} d_{3} & =\text { diameter puli besar }(\mathrm{mm}) \\
\mathrm{s} & =\text { slip pada puli }(\text { diasumsikan } 2 \%)
\end{array}
$$

$$
\frac{1400}{126}=\frac{d_{1} d_{g}}{76_{2} 2 \times 76_{2} 2}\left[1-\left(\frac{2+2+2+2}{100}\right)\right.
$$

$64516=d_{1} d_{3} 0.92$

$d_{1} d_{3}=70126,1$

$d_{l}$ dan $d_{3}=\sqrt{70126,1}=264,8 \mathrm{~mm}=10,42$

Setelah melakukan perhitungan puli bertingkat dengan asumsi $2 \%$ didapatkan bahwa kedua puli besar berdiameter 10,42 in. Karena diameter puli yang ada dipasaran dan paling mendekati dengan hasil rancangan adalah puli berdiameter $10 \mathrm{in}$.

\subsection{Perhitungan Panjang Sabuk}

$$
L=\frac{\pi}{2}\left(d_{p}+d_{m}\right)+2 x+\frac{\left(d_{p}-d_{m}\right)^{2}}{4 x}
$$

Ket :

$\mathrm{L}=$ Panjang sabuk

$d_{p}=$ diameter puli poros $(\mathrm{mm})$

$=10$ in $=254 \mathrm{~mm}$

$d_{m}=$ diameter puli motor $(\mathrm{mm})$

$=3$ in $=76,2 \mathrm{~mm}$

$\mathrm{x}=$ Jarak tengah antara kedua puli $=480 \mathrm{~mm}$

$\mathrm{L}=1478,141 \mathrm{~mm}+16,465 \mathrm{~mm}$

$=1494,6 \mathrm{~mm}$

Dari perhitungan panjang sabuk yang telah dilakukan diperlukan panjang sabuk sebesar 1494,6 $\mathrm{mm}$ atau 58,8 in. Sehingga dapat dibulatkan menjadi 59 in.

\subsection{Gambar Mesin Penghancur Botol Plastik}

Setelah perhitungan segala komponen perancangan dibuatlah mesin penghancur botol plastik ini yang sesuai dari hasil perancangan. Gambar mesin penghancur botol plastik terdapat pada Gambar 6 .

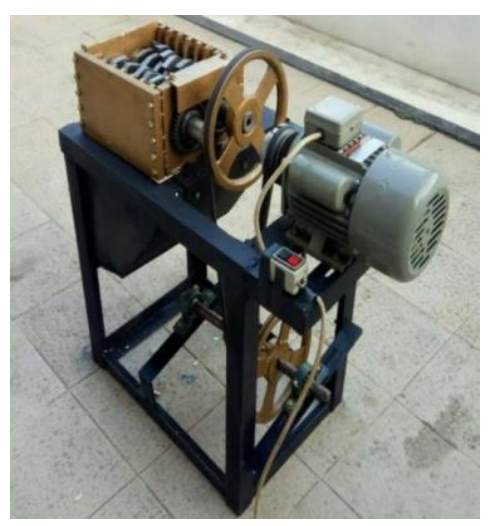

Gambar 6 Mesin Penghancur Sampah Botol Plastik

\subsection{Hasil Pengujian Alat}

Setelah alat dibuat maka akan dilakukan proses pengujian alat dengan memasukkan sampah botol plastik masing-masing seberat $1 \mathrm{~kg}$. Lalu membandingkannya dengan tiga buah bentuk susunan mata pisau yang akan dilihat waktu pemotongan dan ukuran hasil potongannya. Hasil pengujian dapat dilihat pada tabel 2 .

\section{Tabel 2 Hasil Pengujian}

\begin{tabular}{lcccc}
$\begin{array}{c}\text { Bentuk } \\
\text { susunan } \\
\text { Pisau }\end{array}$ & $\begin{array}{c}\text { Berat } \\
(\mathrm{kg})\end{array}$ & $\begin{array}{c}\text { Waktu } \\
(\mathrm{s})\end{array}$ & $\begin{array}{c}\text { Hasil } \\
(\mathrm{kg} / \mathrm{jam})\end{array}$ & $\begin{array}{c}\text { Ukuran } \\
\text { Hasil } \\
\text { Potonga } \\
n(\mathrm{~cm})\end{array}$ \\
\cline { 1 - 4 } Susunan 1 & 1 & 108,22 & 33,26 & $4,5-10$ \\
Susunan 2 & 1 & 112,19 & 32,08 & $4-8,5$ \\
Susunan 3 & $\underline{1}$ & $\underline{110,15}$ & $\underline{32,68}$ & $\underline{4,3-9}$ \\
\hline
\end{tabular}

Dari hasil pengujian yang telah dilakukan, diperoleh waktu paling cepat, yaitu 108,22 detik dengan hasil potongan berukuran $4,5-10 \mathrm{~cm}$ untuk variasi bentuk susunan mata pisau pertama atau yang berbentuk lurus.

Waktu yang paling lambat, yaitu 112,19 detik dihasilkan oleh variasi bentuk susunan mata pisau kedua atau yang berbentuk hampir menyerupai bentuk $\mathrm{X}$, tetapi dapat menghasilkan potongan-potongan yang paling kecil diantara ketiga bentuk susunan pisau yaitu berukuran $4-8,5 \mathrm{~cm}$. 
Sedangkan pada variasi bentuk susunan mata pisau ketiga atau yang berbentuk hampir menyerupai bentuk V membutuhkan waktu 110,15 detik dan memperoleh hasil potongan sebesar 4,3 $9 \mathrm{~cm}$.

\section{KESIMPULAN DAN SARAN}

\subsection{Kesimpulan}

1. Perancangan yang dilakukan sudah sesuai dengan alat penghancur sampah botol plastik yang telah dibangun.

2. Bentuk susunan mata pisau pertama memiliki kapasitas paling besar daripada susunan mata pisau kedua dan ketiga yaitu 33,26 kg/jam.

3. Bentuk susunan mata pisau kedua memiliki ukuran hasil potongan paling kecil daripada susunan mata pisau pertama dan ketiga yaitu 4 $-8.5 \mathrm{~cm}$.

\subsection{Saran}

1. Tingkat ketelitian pada saat pembuatan mesin sangat disarankan karena jarak antar pisau pemotong sangat kecil, sehingga pembuatan yang tidak presisi kemungkinan besar dapat mengakibatkan terjadinya tabrakan dan gesekan yang menyebabkan kegagalan pada pisau pemotong atau bagian-bagian utama mesin lainnya.

2. Penelitian dapat dikembangkan lagi sehingga nantinya poros dapat berubah putaran searah atau berlawanan arah jarum jam sesuai dengan torsi yang diperlukan dengan menambahkan sensor torsi pada poros.

\section{KEPUSTAKAAN}

[1]Yamin, M., Satyadarma, D. \& Naipospos, P. 2008. Perancangan mesin pencacah sampah type Crusher.

[2]Junaidi, nur, I., nofriadi \& rusmardi 2015. Pengembangan Mesin Pencacah Sampah atau Limbah Plastik Dengan Sistem crusher dan silinder pemotong type rel.

[3]Rajagukguk, J. 2013. Analisis perancangan mesin penghancur plastik.

[4]Fadillah, A. 2015. Implementasi peraturan daerah kota samarinda nomor 02 tahun 2011 tentang pengolahan sampah (studi kasus pada dinas kebersihan dan pertamanan kota samarinda).
[5]Sutowo, C., Diniardy, E. \& Maryanto 2011. Perencanaan Mesin Penghancur Plastik Kapasitas 30 kg/jam.

[6] Triantoko, R., Bisri, M. A., Isnaenudin, F., Zulkarnain, R. J. \& Baikhaky, A. A. 2015. Rancang bangun mesin pencacah botol plastik.

[7]Sularso \& Suga, K. 2013. Dasar Perancangan Dan Pemilihan Elemen Mesin, Jakarta, PT Pradnya Paramitha.

[8]Khurmi, R. S. \& Gupta, J. K. 2005. " A Text Book Of Machine Design", (New Delhi, Eurasia Publishing House (Pvt.) Ltd. ). 